\title{
New Possibilities with Improved Green Sand Testing Equipment
}

\section{Hubert Kerber ${ }^{1, a,{ }^{*},}$ Philipp Jakesch ${ }^{1, b}$, Gerhard Schindelbacher ${ }^{1, \mathrm{c}}$, Peter Schumacher ${ }^{1,2, d}$}

\author{
${ }^{1}$ Österreichisches Gießerei-Institut, Parkstr. 21, 8700 Leoben, Austria \\ ${ }^{2}$ Lehrstuhl für Gießereikunde, Montanuniversität Leoben, Franz Josef. Str.18, \\ 8700 Leoben, Austria \\ ahubert.kerber@ogi.at, ${ }^{b}$ philipp.jakesch@ogi.at, 'gerhard.schindelbacher@ogi.at, \\ peter.schumacher@unileoben.ac.at
}

Keywords: Green sand testing; Improved electronic measurements; stress-deformation-curves

Background. The quality of green sand moulds is paramount for the casting quality and reduction of surface defects. The general knowledge within foundries on green sand properties and its influence on casting defect behaviour has significantly decreased as a result of outsourced external sand testing and dependence on external consultants. Moreover, academic R\&D activities targeting studies on green sand properties could not attract significant funding and have hence been limited to small extents. It cannot be stressed enough that in sand casting the majority of casting defects can be related to an insufficient green sand management. Recent research and development has been only supported by suppliers of the foundry industry, however, with a major emphasis on anorganic water glass binder systems and the reduction of phenolic binders in organic binders to reduce emission and unpleasant smells while simultaneously increasing e.g. fluidity or strength $[1,4]$.

In most industrial environments hand-operated sand testing machines, whose basic concepts of operation were developed in the middle of the last century, are still used. While these old fashioned apparatuses can help to maintain quality in a foundry they are not suited to provide additional information on the green sand quality.

Therefore, any developments on different mould materials were mainly performed with very old fashioned manually operated sand testing equipment and a significant aspect of the development of more accurate modern sand testing equipment was neglected. Nevertheless, these manually operated sand testing apparatuses represent the current state-of-the-art of sand testing equipment. In order to improve green sand properties and gain additional knowledge it is essential to develop new testing methods.

This paper will give information on the development of novel green sand testing equipment for compaction, pressure, as well as wet strength testing development at the ÖGI and gives comparison to values obtained by manually operated machines.

The main advantage of modern electronical testing machines is a higher accuracy of measurement in general and the possibility of recording stress-strain-curves.

This work shows characteristic stress-strain-curves for all mechanical green sand testing methods as well as the influence of water content on the progression of mechanical properties. As a result the area with the best handling properties of green sand is shown.

Furthermore negative influences of defective sand specimens and marginal deviations in the testing process on the testing result have been investigated.

\section{Experimental Methods}

Sand mixtures were produced in a rotating pan mill (GF Simpson - SIM 00G ) in $5 \mathrm{~kg}$ batch size with quartz sand (H32 with an average grain size of $0,32 \mathrm{~mm}$ ) a reactive bentonite content of $8 \%$ lustrous carbon addition of $3,5 \%$ and a variable water content from 2 to $4 \%$. The actual water content was measured on a heated scale (Mettler Toledo) after $10 \mathrm{~min}$ at $120{ }^{\circ} \mathrm{C}$. Sand mixtures were stored in sealed plastic bags and airtight buckets with lids to avoid water loss to maintain constant moisture. Samples for sand testing were prepared according to the VDG guidelines with a 
typical sample diameter of $50 \mathrm{~mm}$ and a height of $50 \mathrm{~mm}$ obtained after 3 impacts on a sample impactor (GF). To access the influence of compacting method, samples were additionally impacted repeatedly or pressed. The obtained sand sample were carefully placed in a universal multipurpose material testing machine (Zwick Z005 proline) in which adapted sample holders according to the VDG Guidelines were mounted [2]. (see Figure 1)
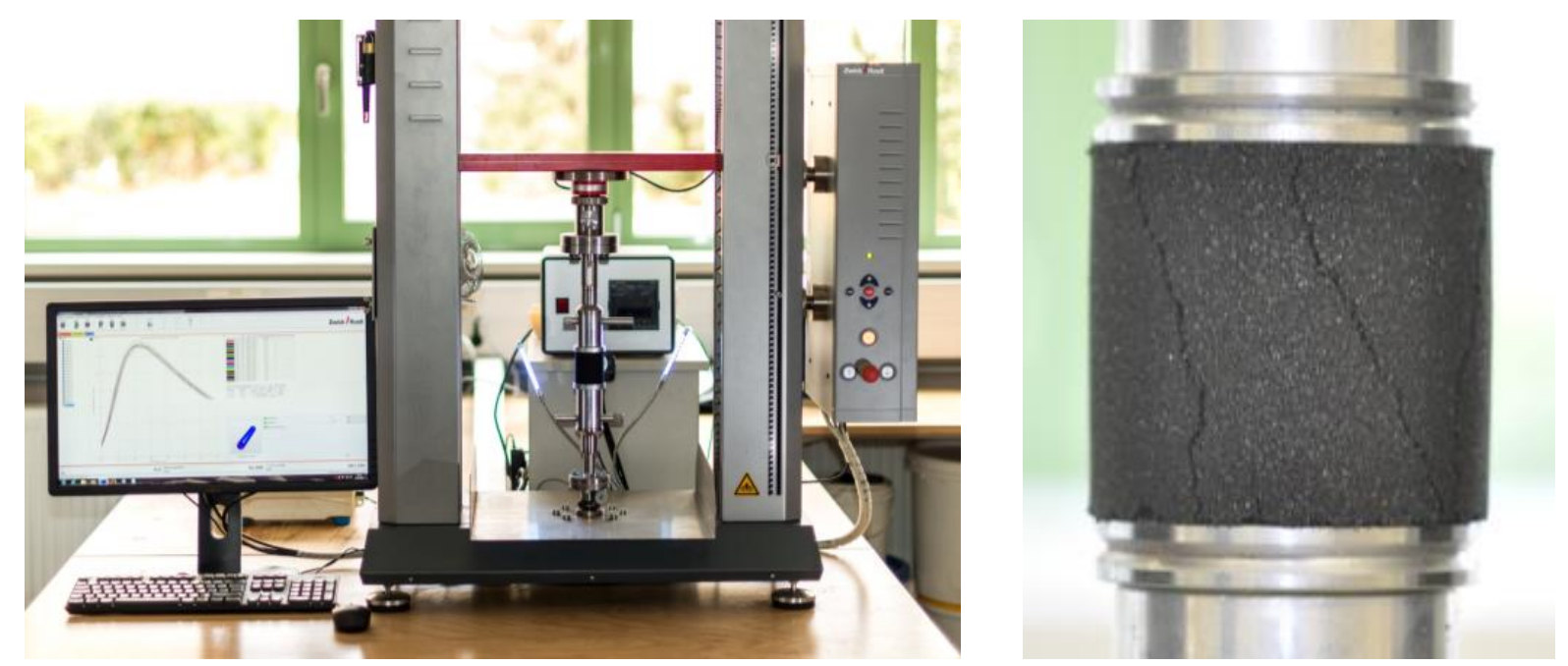

Figure 1: Universal testing machine up to $5 \mathrm{kN}$ and sample holder for compressive strength testing

\section{Results}

Typical compacting curves are shown in Figure 2 for samples with varying water content. The compaction of the granular samples follows a continuously increasing curve until a cut off value of $2000 \mathrm{~N}$ is reached. In Figure 2 it can clearly be seen that an increasing water content facilitates a much improved compactibility above $50 \%$ for the present sand system.

In Figure 3 is shown the compressive strength against the deformation for different water contents. It is interesting to note that the highest water content does not lead to the highest strength despite the previously observed best compactibility. However, a trend can be seen in that a higher water content leads to an increased deformation at the maximum observed compressive strength. 


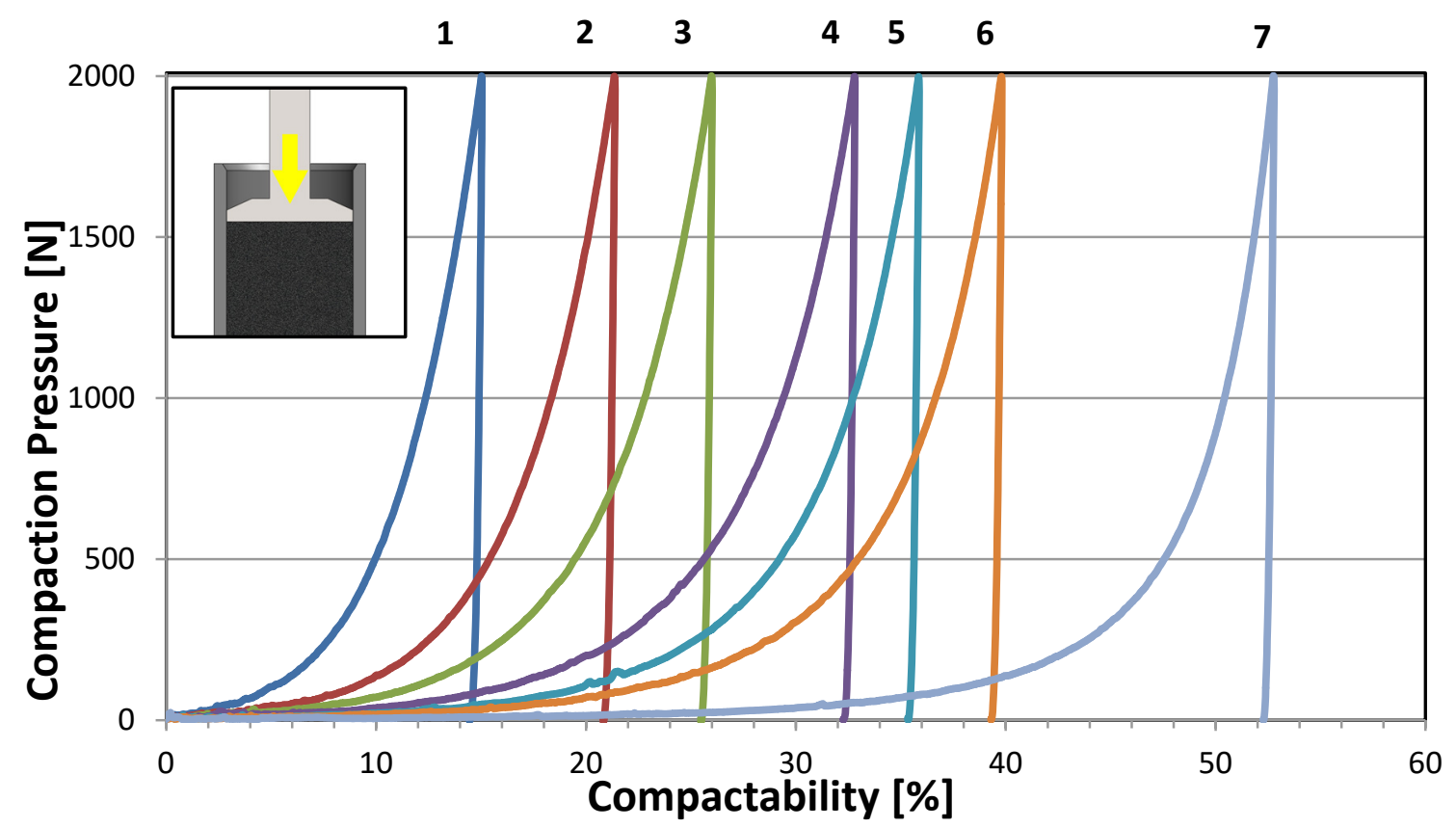

Figure 2: Testing the compactibility: Pressure-deformation-curves show raising compactibility with raising water content. (graph explanation: 1 - 1,97\% $\mathrm{H}_{2} \mathrm{O} ; 2$ - 2,22\% $\mathrm{H}_{2} \mathrm{O} ; 3$ - 2,56\% $\mathrm{H}_{2} \mathrm{O} ; 4$ $2,90 \% \mathrm{H}_{2} \mathrm{O} ; 5$ - 3,03\% $\mathrm{H}_{2} \mathrm{O} ; 6$ - 3, $15 \% \mathrm{H}_{2} \mathrm{O} ; 7$ - 4,04\% $\mathrm{H}_{2} \mathrm{O}$ )

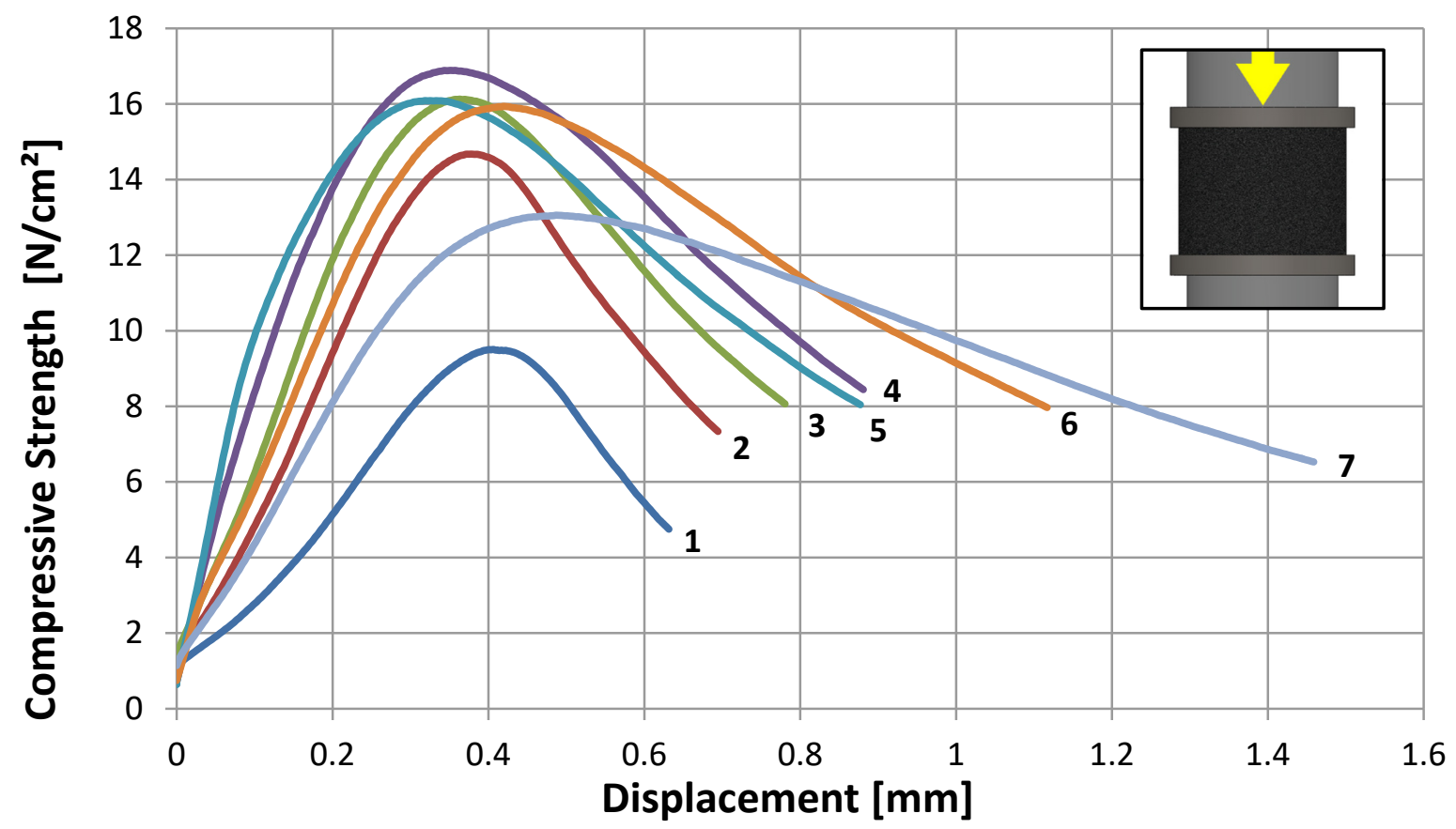

Figure 3: Testing green compressive strength: While increasing moisture content increases the green compressive strength at first, the strength is reduced when the water content exceeds the value of $3 \%$. Increasing water content results in growing ductility of the sand. (graph explanation: 1 -

1,97\% $\mathrm{H}_{2} \mathrm{O} ; 2$ - 2,22\% $\mathrm{H}_{2} \mathrm{O} ; 3$ - 2,56\% $\mathrm{H}_{2} \mathrm{O} ; 4$ - 2,90\% $\mathrm{H}_{2} \mathrm{O} ; 5$ - 3,03\% $\mathrm{H}_{2} \mathrm{O} ; 6$ - 3,15\% $\mathrm{H}_{2} \mathrm{O}$;

$$
7-4,04 \% \mathrm{H}_{2} \mathrm{O} \text { ) }
$$

The greatest influence of the water content can be seen in Figure 4 for the splitting strength which gives qualitative information on the tensile properties. Initially the splitting strength increases with water content to a maximum value close to $3 \%$ and then decreases. Again a greater deformation can be observed for higher water concentrations in the sand samples. 


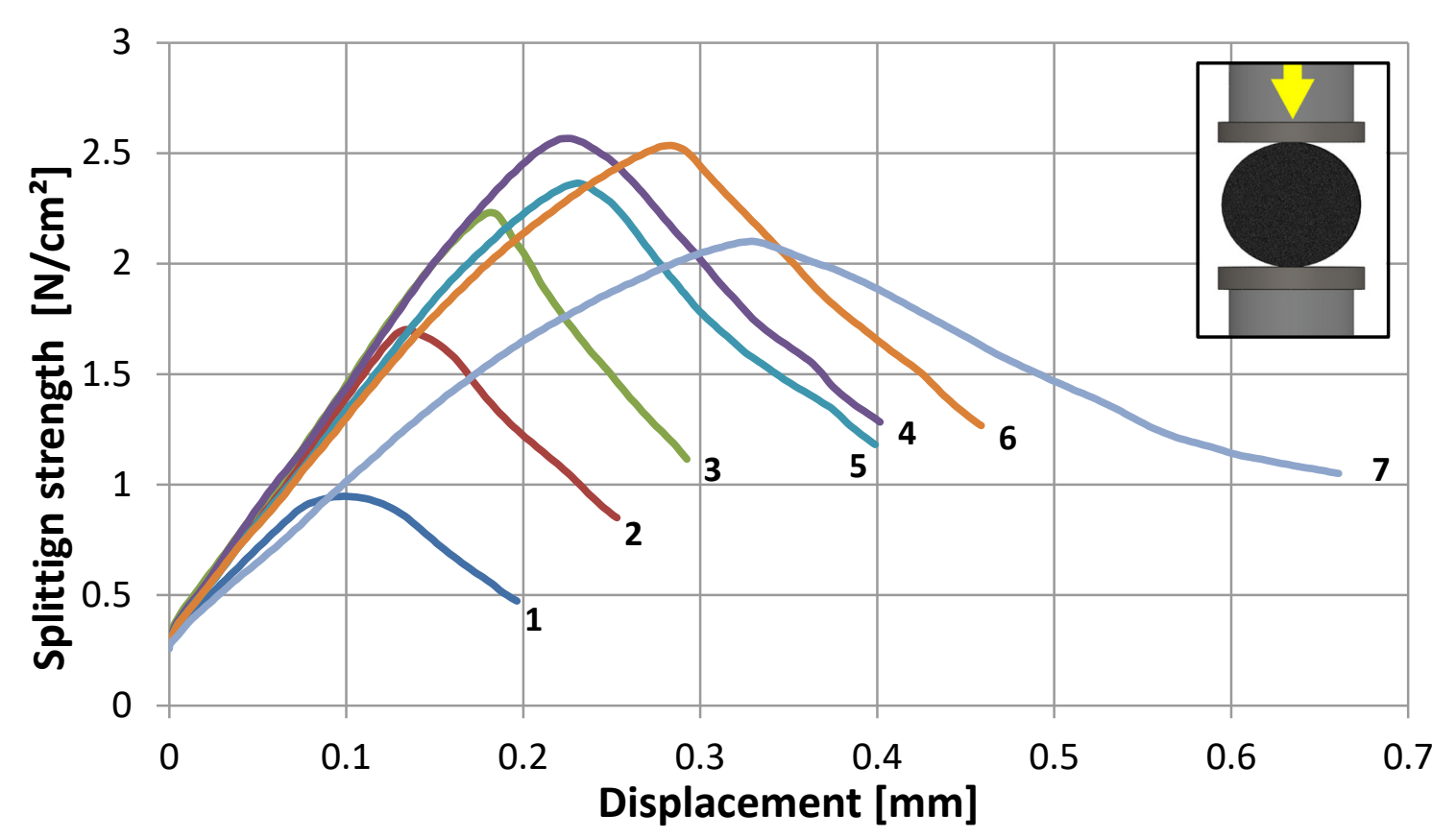

Figure 4: With more than $3 \%$ humidity the strength values decrease but the deformation potential is higher. (graph explanation: 1 - 1,97\% $\mathrm{H}_{2} \mathrm{O} ; 2$ - 2,22\% $\mathrm{H}_{2} \mathrm{O} ; 3-2,56 \% \mathrm{H}_{2} \mathrm{O} ; 4$ - 2,90\% $\mathrm{H}_{2} \mathrm{O} ; 5$ -

$$
\left.3,03 \% \mathrm{H}_{2} \mathrm{O} ; 6-3,15 \% \mathrm{H}_{2} \mathrm{O} ; 7-4,04 \% \mathrm{H}_{2} \mathrm{O}\right)
$$

In Figure 5 tensile properties of the sand samples with increased water concentrations are illustrated. A similar stiffness is observed for all samples while the maximum strength increases with water content up to $3.15 \%$. In this geometry of the given strength test (see insert Figure 5) actually the resistance against a notch is tested compared to a dog bone geometry. Clearly if the sand can deform the effect of the notch can be compensated until the bond strength between sand grains is negatively influenced by the increased water content. 


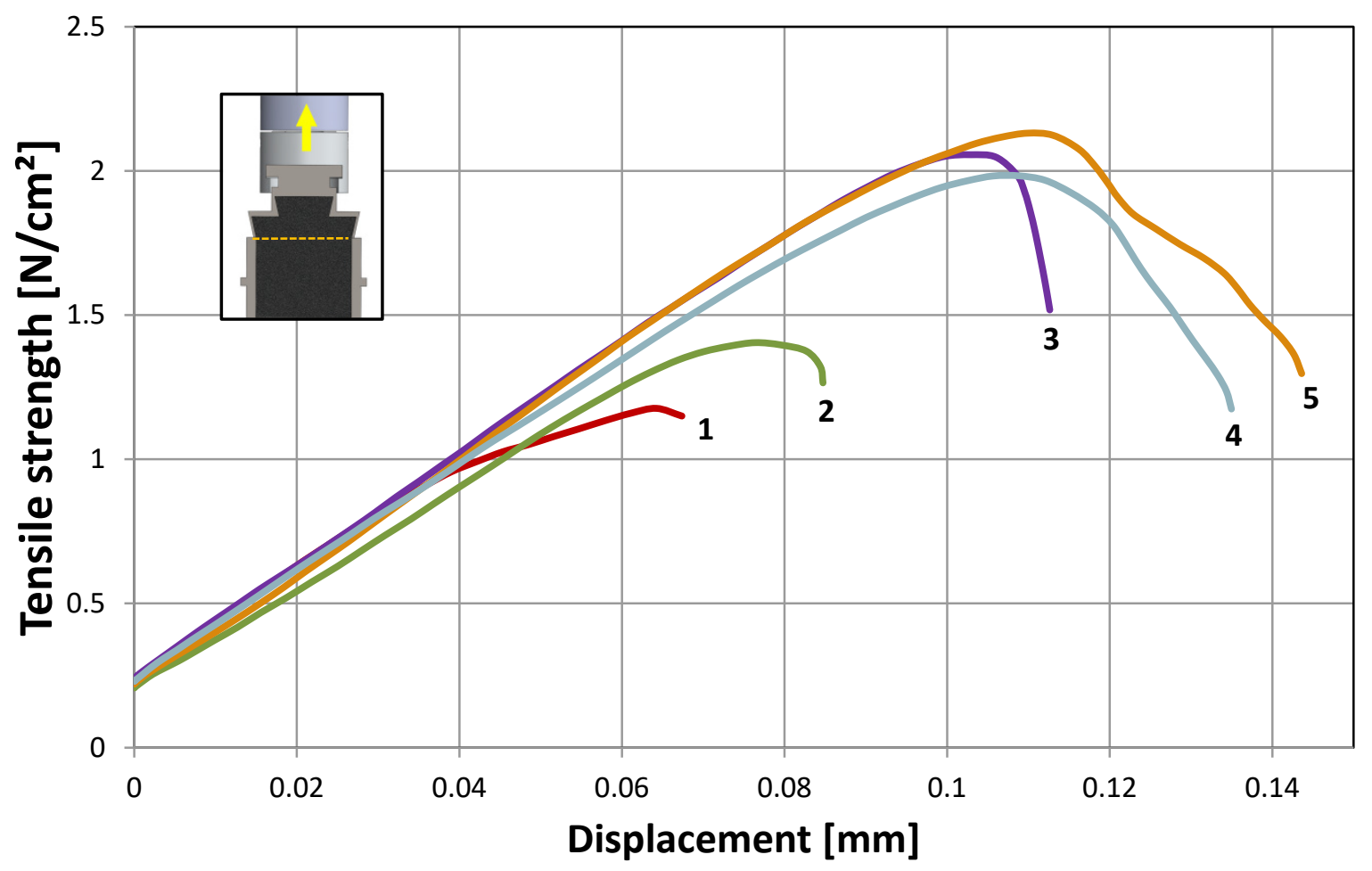

Figure 5: The tensile test curves show an accurate linear modulus of elasticity. With increasing humidity also strength and plasticity increase. (graph explanation: $1-2,22 \% \mathrm{H}_{2} \mathrm{O} ; 2-2,56 \% \mathrm{H}_{2} \mathrm{O}$;

$$
3 \text { - 2,90\% } \mathrm{H}_{2} \mathrm{O} ; 4 \text { - 3,15\% } \mathrm{H}_{2} \mathrm{O} ; 5-4,04 \% \mathrm{H}_{2} \mathrm{O} \text { ) }
$$

With new testing equipment not only the maximum strength values can be detected but also the progression of the strength versus displacement curves. The dependency between water content and the mechanical properties can clearly be demonstrated. The strong influence of the water content on the compressive strength can be seen in Figure 6. Previous $[2,5,6]$ and our present work have shown that the ideal working area to obtain best sand moulds in practice is located after exceeding the strength maximum. This combines a negligible loss in strength but an essential gain in deformability. 


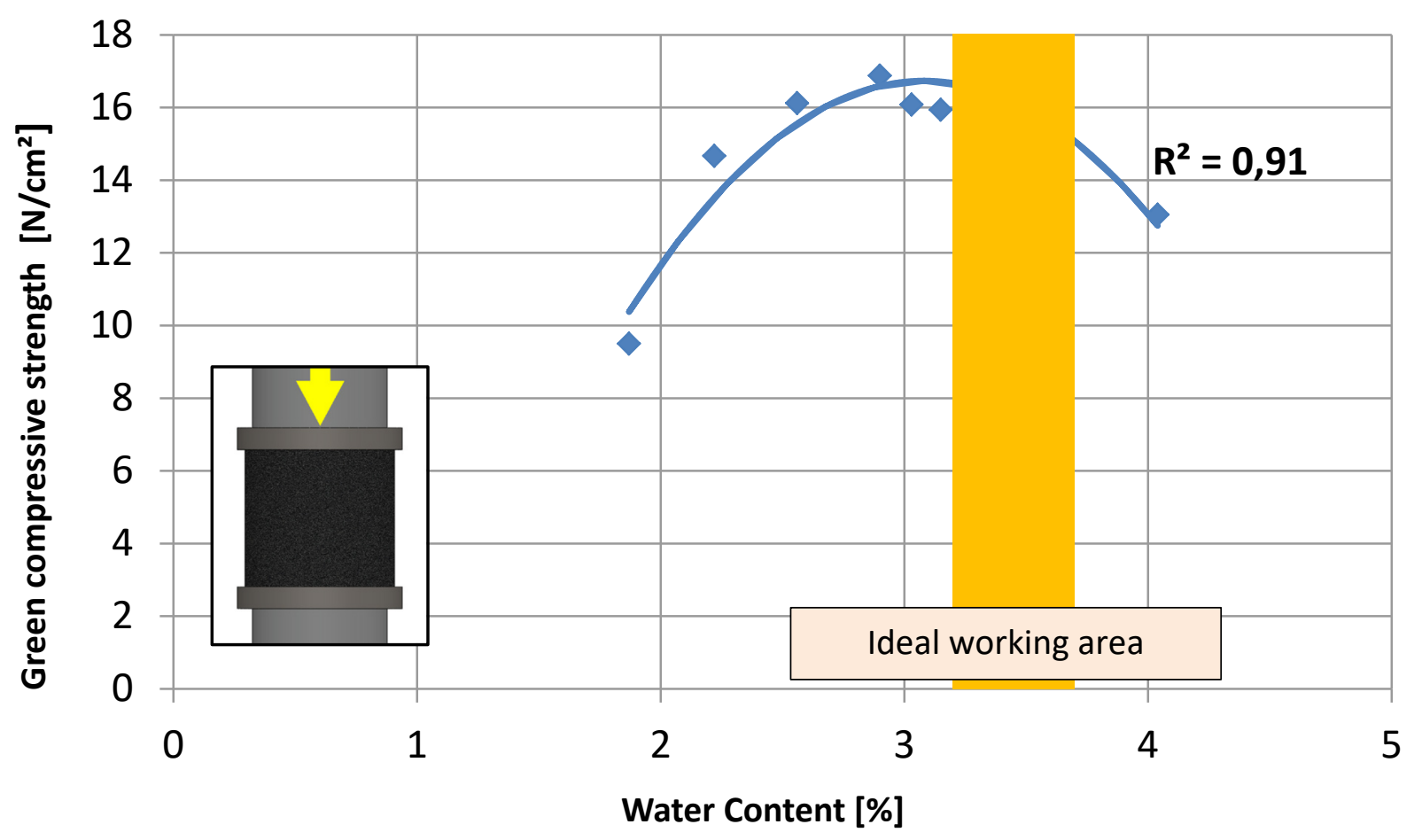

Figure 6: The ideal working area is characterised by slightly less compressive strength with higher deformability

In the previous results emphasis was on the practical side to use good samples only. However, there are strong effects on the mechanical properties of good sand mixtures by poor handling and preparation of sand samples. Typical defects which can be encountered in the testing of sand samples in foundry practice are given below and illustrated in Figure 7.

- $\quad$ Defective sample surfaces due to careless handling

- Insufficient time between single ram compacting strikes

- Jerky removal of test samples from the compaction cylinder

- Loss of water content due to drying of the green sand mixture in non-airtight storage

- Incorrect height compaction of testing samples
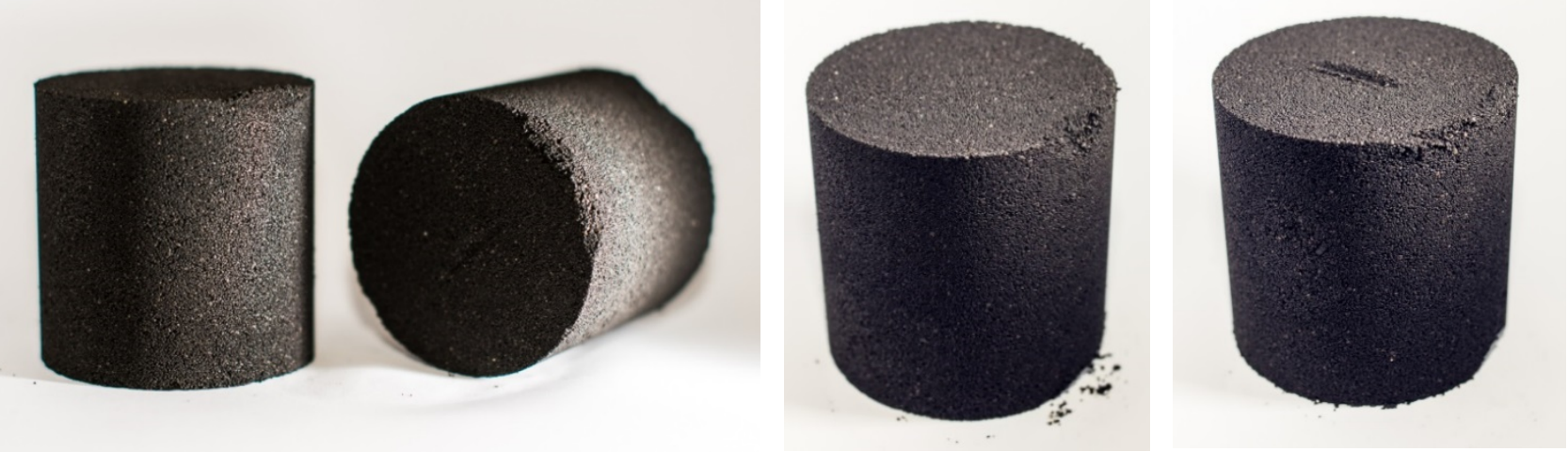

Figure 7: Introduced scratches and edge defects on sand testing samples

A comparison of 40 samples of identical height but deliberately introduced defects such as scratches, broken edges etc. are given in Figure 8. In Figure 8 a strong variation in the maximum obtained strength and its displacement can clearly be observed. Moreover, the onset at which strength is transferred from the sample onto the testing machines varies to a great extent. In extreme cases identical sand mixtures can give totally different values for mishandled but delicate test samples. 


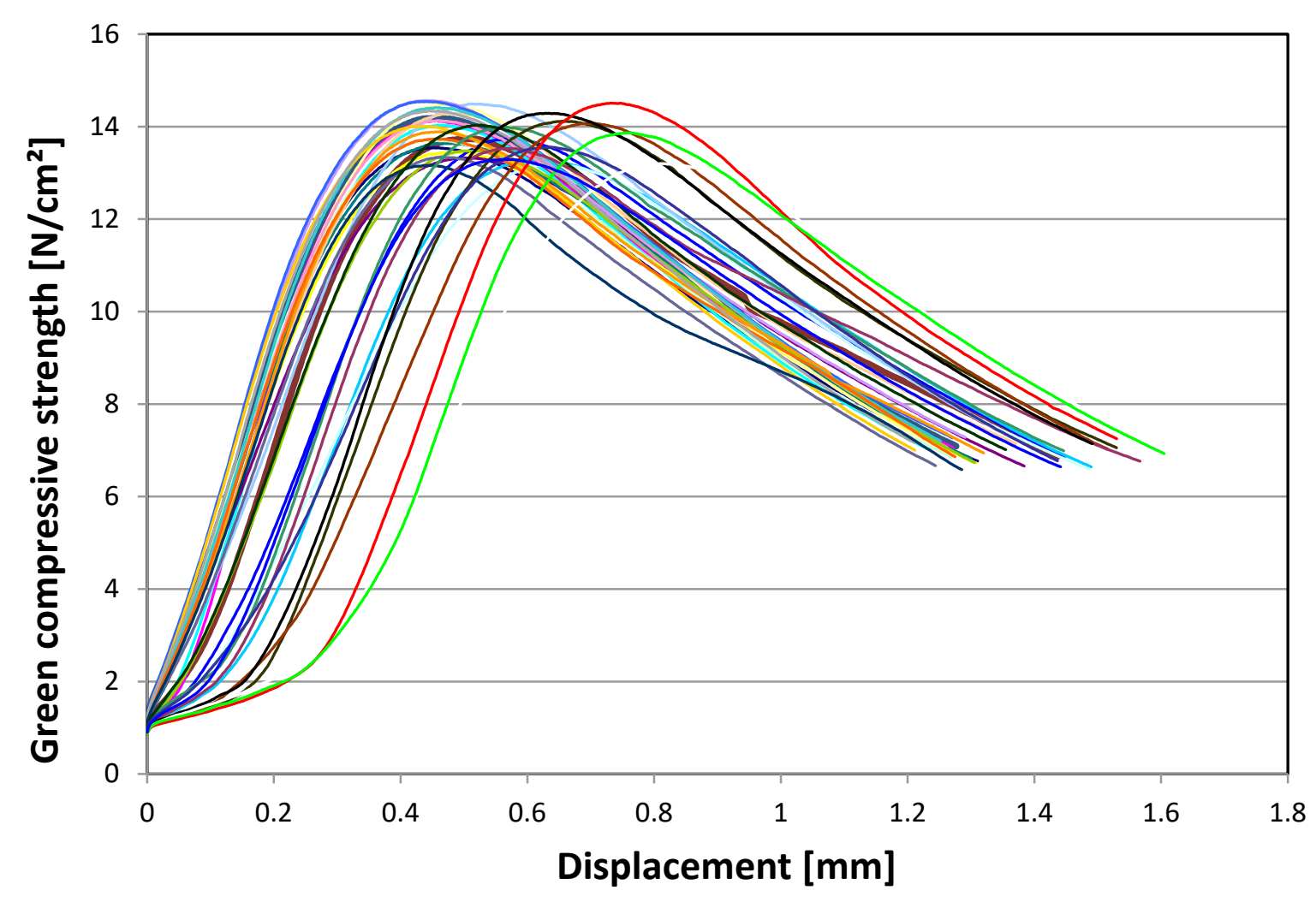

Figure 8: 40 samples of a homogeneous sand mixture with deliberately introduced defects (specimen always with same height)

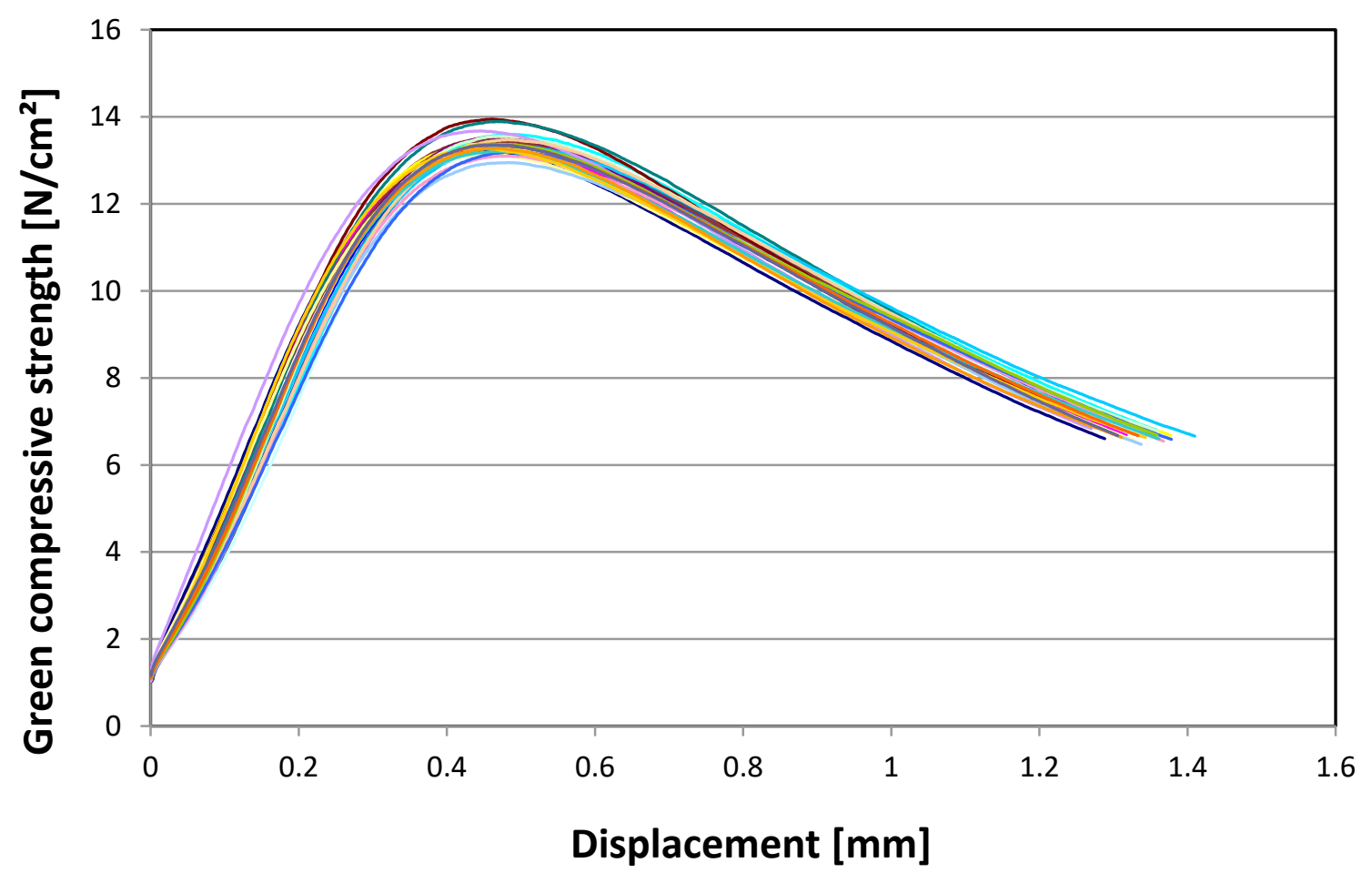

Figure 9: 25 Accurately prepared and tested samples of a homogeneous sand mixture

In contrast, if sand samples are prepared and tested correctly, test curves show a high degree of reproducibility. In Figure 925 sand samples show a neat agglomeration of test curves within the measurement errors expected for the applied procedure. While there is little deviation in the maximum observed in strength even less scatter is observed for the displacement at which maxima 
occur. In order to obtain such neat testing results care has to be taken with the sample preparation. In particular the following points must be addressed:

- $\quad$ Take care for an accurate weight of test specimen for a correct height of $50+0.3 \mathrm{~mm}$

- $\quad$ Avoid even small damage of test specimens

- $\quad$ Store the sand before and while testing in dense bags or buckets to avoid loss of moisture

- $\quad$ Note the different methods of compacting green sand specimens: Rammed and pressed specimens are not comparable; they result in different strength values

\section{Conclusions}

- Conventional sand testing can only measure maximum values!

- Improved electronic measurements with stress-deformation-curves give additional information:

○ Resistance against displacement (Young's-Modulus)

- Maximum values and plastic behaviour

- Defective specimens show deviations in the curve progression

- Maximum values of conventional testing apparatus and improved electronical testing methods compare well

- Improved methods can give information on the green sand material property relationships

\section{References}

[1] G. Schindelbacher, H. Kerber, M. Riegler und M. Berbic; Umfassende Charakterisierung von Formstoffen mit einer neuen Prüfmethode; GIESSEREI 100 (09/2013), 40-49

[2] O. Podobed: Giesserei-Rundschau 60 (1-2/2013), 72

[3] VDG-Merkblatt P38, Prüfung von tongebundenen Formstoffen; Bestimmung der Festigkeiten, 1997

[4] B. J. Stauder, H. Kerber, P. Schumacher; Foundry sand core property assessment by 3-point bending test evaluation; J Mater Process Tech, Volume 237 (2016), 188-196.

[5] H. Kerber; Proben pressen oder Proben rammen: Einfluss der Prüfkörperdichte auf die Formstoffeigenschaften; Gießerei Rundschau 61 (3/4/2014), 97 - 102

[6] H. Kerber, P. Feldhofer, G. Schindelbacher; Mechanische Eigenschaften von Nassgusssand: Erweiterte Erkenntnisse durch Spannungs-Verformungs-Kurven; Gießerei Rundschau 64 (03/2017), $19-25$ 